\title{
Sweet are the fruit of adversity? The impact of fathers' death on child non-cognitive outcomes in Ethiopia
}

\section{Author: Rozana Himaz}

\begin{abstract}
This article looks at the effect paternal death can have on non-cognitive outcomes at age 15 and 22 depending on whether a child lost the father in middle childhood or adolescence. The article uses the potential outcome framework to estimate results using five rounds of longitudinal survey data for Ethiopia collected between 2002 and 2016. It finds that the loss of the father in middle childhood reduces an orphan's self-esteem significantly by 0.15 standard deviations and subjective wellbeing by 16 per cent. These effects are not persistent. Instead, the loss of the father between ages 12-22, encompassing early, middle and late adolescence have significant positive effects on agency, self-efficacy, self-esteem and peer relationships as a young adult aged 22 , improving them by $0.31,0.28,0.31$ and 0.26 standard deviations respectively. This suggests that a father's death during a child's adolescent years may be associated with positive adaptive behavior.
\end{abstract}

Key words: Ethiopia, Orphanhood, Non-cognitive outcomes, adolescence, psychosocial

\section{Introduction}

Nearly 140 million children under 18 years of age had lost one or both parents due to any cause of death in 2015 with around 37 per cent from Africa (UNICEF, 2016). Children who lose one parent ('single orphans') or lose both parents ('double orphans') are a vulnerable 
group with outcomes such as schooling and earnings when adults all potentially more negative compared to those of non-orphans (Beegle, De Weerdt, \& Dercon, 2009; Evans \& Miguel, 2007). The gender of the parent that died can be very important to these outcomes. For example, Case and Ardington (2006) show that the loss of a child's mother is a strong predictor of schooling outcomes in South Africa. Similar results are found for Taiwan (Chen, Chen, \& Liu, 2009; Gimenez, Chou, Liu, \& Liu, 2013). However, no evidence is found of maternal death reducing primary school completion rates in North Western Tanzania (Ainsworth, Beegle, \& Koda, 2005). With regard to fathers, Cas et. al. (2014) who investigate children orphaned by the 2004 boxing data tsunami in Aceh, Indonesia find that in the longer term (i.e., five years later) the loss of only the father has negative impacts on school enrolment and years of completed schooling for older males aged 15-17 at baseline than similar males whose parents survived the tsunami. There was little evidence that parental death affected human capital accumulation of those who were aged 9-14 in 2004. Maternal death had little impact on schooling outcomes of children but did affect their time allocation. Shenk and Scelza (2012) find that the loss of a father later in a child's teenage years can have significant negative impacts on various outcomes in India including education, income and high quality spouses, as investments by fathers are particularly important in adolescence in that specific social context. Thus gender of parents who died, the age of child at the time of death and the social and developmental context seem to be important in influencing outcomes later in life. Moreover, orphanhood need not inevitably result in negative outcomes if suitable care-giver arrangements, economic assistance and other protective factors are prevalent as noted by Abebe and Aase (2007) in a qualitative study of 42 Ethiopian orphans.

In spite of such investigations, little empirical evidence exists -especially for developing countries- regarding how the loss of the father may matter to non-cognitive skills 
and how these impacts may vary according to the time in a child's life-course during which the father died. Non-cognitive skills can be defined as the 'patterns of thoughts, feelings and behaviours' (Borghans, Duckworth, Heckman, \& Weel, 2008) that are socially determined and can be developed throughout the lifetime to produce value. They include psychosocial skills such as self-esteem and self-efficacy, personality traits such as conscientiousness and motivation and more broadly soft skills particularly useful in the labour market such as teamwork and perseverance (Heckman \& Kautz, 2012). These attributes are not adequately measured by Intellectual Quotient (IQ) tests or achievement tests. If orphans do step into adulthood with significantly poorer non-cognitive outcomes they are likely to perpetuate into persistent inequalities in other spheres as well, such as standard of living as non-cognitive skills are a conduit for success in the labour market (Heckman \& Kautz, 2012).

The main aims of this article therefore are to investigate empirically, using the case of Ethiopia, how (a) non-cognitive outcomes at age 15 can be different depending on whether a child becomes a single orphan by losing a father in middle childhood (between ages 7-12) or early adolescence (between ages 12-15) and (b) how non-cognitive outcomes at age 22 can be different depending on whether a child becomes a single orphan by losing the father in middle childhood or adolescence defined more broadly (between aged 12-22) ${ }^{1}$. As far as the author is aware, the issue has not been investigated empirically previously for developing

\footnotetext{
${ }^{1}$ Defining clear age boundaries for middle childhood and adolescence is difficult as recognised in the paediatric and medical literature. See for example Sawyer, Azzopardi, Wickremarathne, \& Patton (2018), who define adolescence as ranging from 10 to 24 years and outline the debate surrounding other ranges that can be adopted. See also the author's reply and references therein. Discussing this literature is beyond the scope of this paper and the boundaries adopted capture broadly middle childhood (7-12), early adolescence (12-15), middle (15-19) and late adolescence (19-22) matching the average age the index child of the data used.
} 
country contexts. The focus is on paternal death rather than maternal death mainly due to data constraints, as explained in more detail later on in the paper. The data come from five rounds of the Young Lives longitudinal survey, conducted in 2002, 2006, 2009, 2013 and 2016 tracking a sample of around 3000 children from poorer households across 20 sentinel sites in Ethiopia $^{2}$. The data set allows for the investigation of various non-cognitive outcomes at ages 15 and 22 and control for a rich set of pre-orphanhood characteristics.

The paper uses the potential outcome framework to extract the average treatment effect on the treated using the inverse probability weighting with regression adjustment (IPWRA) estimator as described in (Cattaneo, 2010; Wooldridge, 2010). The treatment is multivalued rather than being binary as it depends on the time during a child's life-course during which the father died. A key empirical challenge is to disentangle correlation from causality as parental death is not an entirely random event. If a father's death is correlated to unobserved characteristics such as attitudes to health or omitted variables then a comparison of observed outcomes between single orphans and non-orphans will not necessarily reflect the true effect of orphanhood. For example the effects of being orphaned may be overestimated if fathers' unobserved health problems or risk preferences affect children's development as well as contribute to the parent's death. On the other hand if becoming a paternal orphan lead to the child dying or being attrited in-between rounds of a longitudinal survey, the measured impact could be an underestimate. We address the issues of sample selection and omitted variable bias, to some extent at least, by using a rich set of observed pre-orphanhood characteristics in the analysis and estimations. Even so, if paternal death was

\footnotetext{
${ }^{2}$ The Young Lives survey also tracks children from India, Peru and Vietnam. We do not include the latter two countries in the present study as the number of children orphaned is too small and the estimations may not have sufficient statistical power. We exclude India because orphanhood seems correlated with variables associated with poverty in the sample for India, biasing estimations.
} 
not unanticipated and preceded by ill health, it could have affected outcomes prior to death (through unemployment, hospitalisation, requiring care at home or changes to the quality of parenting during the survival time). This would mean the estimates are biased. In our sample, around 16 per cent of the households that report a father's death in a particular round also report that the parent was seriously ill between that round and the preceding one- a number not so small that it can be safely assumed that paternal death was sudden across the entire sample ${ }^{3}$. Moreover, even if death was sudden, attributing causal effects is difficult as there could still be unobservables that are correlated with both child outcomes and parental death. Thus the more modest claim this paper makes is that it identifies correlations and patterns associated with death rather than strictly causal relationships.

The rest of this paper is organised as follows. The next section discusses the conceptual framework while section 3 looks at data and descriptive statistics, section 4 looks at results taken from the baseline and alternative specifications while section 5 concludes.

\section{Conceptual Framework}

\footnotetext{
${ }^{3}$ As noted by an anonymous referee, the 16 per cent maybe underestimate the percentage of fathers whose death may have been anticipated due to prior illness. This is because identifying whether the father suffered from illness is based on the 'shocks' section of the survey that asks the respondent (the child's primary caregiver in most cases), about 'the most important events and changes that "affected the household economy negatively" since the last time we came to see you', with last time referring to the previous round of the survey. It is up to the respondent to interpret what "affected the household negatively" actually means. For example, if the father had been ill for a long time, even before the previous round 3-4 years ago, then the respondent may choose to ignore the father's illness as an event affecting household economy. If this is the case then we may be over-estimating the incidence of sudden death in our sample. It should be noted, however, that 'suddenness' of death is not essential to the narrative as causality is not claimed.
} 
Why might non-cognitive outcomes as an adult be very different depending on which point in a child's life course a father died? The answer may lie in the different ways in which noncognitive development is influenced in the life course. From a child's development perspective, middle childhood is a crucial stage where roles and responsibilities evolve together with cognitive skills such as learning and reasoning and non-cognitive aspects such as interpersonal negotiation and problem solving (Feinstein \& Bynner, 2004; Grigorenko, 2017; Papalia, Olds, \& Feldman, 2007). A child's family, school, peers and overall context that are important to this development can be disrupted due to paternal death. For example there could be a change in caregiver arrangement or extra stress placed on the mother with increase perhaps in anxiety, depression and consequent changes to parental behaviour, or increase in chores and work a child has to carry out. There could be income effects too that adversely affect the acquisition of cognitive skills if schooling is affected. The effects of changes to context may matter differently to development at different stages of life but an earlier disruption in middle childhood may possibly have more lasting consequences than a later disruption, particularly as middle childhood is still a phase in life when children are not seeking autonomy from parents.

Another reason to hypothesise that the timing of the 'shock' to a child's life would matter for the development of personality traits comes from a neurological perspective. Teenage years in particular are a time of rapid change, presenting a 'perfect storm' with simultaneous and sudden increases in hormonal, neural and social changes as well as changes in personality development as one's sensitivity to social signals in the environment are enhanced (Blakemore \& Mills, 2014; Eric E. Nelson, Jarcho, \& Guyer, 2016). It is also a phase in the life course where children seek more independence and autonomy from parents (Eccles et al., 1993; Steinberg \& Morris, 2001) and tend to look for loyal, close friendships from peers (Brown, 2004; Eric E. Nelson et al., 2016; E. E. Nelson, Leibenluft, McClure, \& 
Pine, 2005). This social reorientation supports, more generally, the emergence of social competence and social functioning (Capaldi, Dishion, Stoolmiller, \& Yoerger, 2001). In social contexts where within household interdependencies are strong and teenagers play an important in mitigating household hardship through engaging in work as in Ethiopia (Heissler \& Porter, 2013) a teenager's response to an adversity such as paternal death through work or forming strong peer networks may be a source of protection that fosters specific skills. As Boyden (2009, p. 117) notes, 'identifying adversity is not straightforward because beliefs affect the outcomes of such experiences, and different cultures and actors hold different views on the matter, so that assumed risks can in some cases be protective and foster specific competencies in the young.' This could mean that parental death during adolescence in particular may positively impact the development of personality traits and peer relationships and perhaps even be a source of resilience i.e., 'good outcomes in spite of serious threats to adaptation or development' (Masten, 2001, p. 228), facilitating positive adaptive behaviour, particularly if the developmental context is minimally disrupted (Gore \& Eckenrode, 1996). But adolescents are also inclined to engage in more risky behavior and parental death may encourage this even more especially if the quality of parenting offered by the remaining parent diminishes or the developmental context is disrupted, increasing the likelihood of delinquency and/or substance use amongst the older children.

Finally, parental death later in adolescence or early youth, may be a time when a change in context may have a direct and perhaps immediate impact in influencing a teenager's aspirations and goals (and those of her family's) regarding her future. Thus schooling may be cut short abruptly to give way to joining the labour market full time (Cas et al., 2014). Decisions regarding marriage may be hastened (Beegle \& Krutikova, 2008) or different in terms of 'quality' especially in societies where parental investment later in adolescence matters to finding a higher quality spouse for the child (Apostolou, 2010; Beegle 
\& Krutikova, 2008). Again the impact this may have on cognitive skills is not clear. Even if a child's aspirations and goals are revised, positive adaptive behaviour, if facilitated might lead to positive non-cognitive outcomes at least in some spheres.

\section{Measuring non-cognitive outcomes}

The non-cognitive outcomes that this paper considers at age15 are agency, self-esteem and subjective wellbeing. Agency refers to the power or ability to influence one's life and related to the concept of 'locus of control' as discussed in (Rotter, 1966). Self-esteem is an evaluation of self-worth which follows an adapted version of the self-esteem Scale in Rosenberg (1965), tailored to suit a context of child poverty and specific dimensions of the child's living circumstances (e.g., housing, clothing, work, school). Subjective wellbeing looks at overall life satisfaction measured using an adapted version of Cantril's 'ladder' (Cantril, 1965) that asks the child, where she places herself on a ladder of one to nine rungs with the lowest and highest rungs reflecting the worst and best possible outcomes in life.

The non-cognitive outcomes considered at age 22 are age-appropriate items that measure labour market readiness, skills and other behavioural traits. Labour market readiness is captured in terms of leadership ability and cooperative teamwork ability using subscales of the Review of Personal Effectiveness with Locus of Control (Richards, Ellis, \& Neill, 2002) aimed mainly at measuring social abilities and self-conceptions of relationships with peers (Marsh \& Oneill, 1984). Also measured are skills that predict achievement such as perseverance of effort and consistency of interest that this paper terms 'grit' (Duckworth \& Quinn, 2009). Personality traits measured such as conscientiousness (tendency to be organized and responsible and hardworking) is a subscale from the Big Five personality tests (King \& Watkins, 2012). Other non-cognitive skills include self-efficacy, agency, self-esteem and subjective wellbeing. Self-efficacy looks at coping with daily hassles as well as 
adaptation after experiencing all kinds of stressful life events (Schwarzer and Jerusalem 2010). The other three measures were described previously and are comparable between the 15 and 22 year olds as the survey instruments were the same. Table 1 provides further details on the instruments used to calculate the non-cognitive outcomes used. All instruments are standardised z-scores with a higher score reflecting a more favourable outcome, apart from subjective wellbeing that ranks from 1 to 9 , ranging from least to most favourable outcome.

\section{Data and Summary Statistics}

The data for this paper come from the older and younger cohort data for the Young Lives longitudinal survey data for children, households and their communities collected in 2002, 2006, 2009, 2013 and 2016 for Ethiopia ${ }^{4}$. The sample is largely pro-poor, as the aim of the Young Lives project is to look at the causes and consequences of childhood poverty. However, a careful analysis of the distribution of child characteristics included in the sample suggests that the data covers a wide variety of children in terms of wealth, consumption, similar to nationally representative datasets. Therefore, while not suited for simple monitoring of child outcome indicators (as the mean characteristics will be different), the Young Lives sample is an appropriate for analysing correlates, causal relations and dynamics (Outes-Leon, I., \& Dercon, 2008).

The survey adopted a multi-stage sampling procedure where 150 households each were selected from 20 sentinel cites. A thousand of these households contain children belonging to the 'older cohort' aged 7-8 at the time the first round of data was collected in 2002 (round 1). Two thousand children belonging to the 'younger cohort' were 7-8 years old

\footnotetext{
${ }^{4}$ See https://www.younglives.org.uk/.
} 
at the time the third round of data was collected in 2009 (round 3). Data for these 'index children' from the older and younger cohorts were collected again when they were 11-12 years of age in 2006 and 2013 respectively, and then again at 14-15 years in 2009 and 2016, respectively. 
Table 1: Survey questions used to build psychosocial outcome indices

\begin{tabular}{ll}
\hline Index Name & Survey questions used \\
\hline Panel A: Outcomes at age 15 ( using round 3 questionnaire for the older cohort and round 5 questionnaire for the younger cohort \\
\hline Self Esteem, compatible with & I am proud of my clothes; I am proud of the work I have to do; I feel my clothing is right for all \\
questions in previous rounds of & occasions; I am proud of my shoes or of having shoes \\
data. Scale:1-5 & Other people in my family make all the decisions about how I spend my time; I have no choice \\
Agency, compatible with & about the type of work I do- I must do this sort of work; If I try hard I can improve my situation \\
questions in previous rounds of & in life; I like to make plans for my future studies and work; If I study hard at school I will be \\
data Scale:1-5 & rewarded by a better job in the future
\end{tabular}

Panel B: Outcomes at age 22 (using round 5 questionnaire for older cohort)

\begin{tabular}{ll}
\hline Self Esteem, Agency & See above. \\
Self Efficacy & If someone opposes me, I can find the means and ways to get what I want; When I am confronted \\
Scale:1-4 & with a problem I can usually find several solutions h; If I am in trouble, I can usually think of a \\
& solution; I am confident that I can deal efficiently with unexpected events; I can always manage \\
& to solve difficult problems if I try hard enough; It is easy for me to stick to my aims and
\end{tabular}


accomplish my goals; I can remain calm when facing difficulties because I can rely on my own coping abilities; I can usually handle whatever comes my way; Thanks to my resourcefulness I can handle unforeseen situations; I can solve most problems if I invest the necessary effort

\section{Peer Relations}

Scale: $1-4$

Conscientiousness Scale:1-4

Grit

Scale: $1-4$
I make friends easily; I am popular with kids of my own age; Most other kids like me; Other kids want me to be their friend; I have more friends than other kids; I have lots of friends; I am easy to like; I get along with other kids easily

I am someone who does a thorough job; I am someone who can be somewhat careless; I am someone who is a reliable worker; I am someone who tends to be disorganised; I am someone who tends to be lazy; I am someone who persevered until the task in finished; I am someone who does things efficiently; I am someone who makes plans and follows through with them; I am someone who is easily distracted.

New ideas and projects sometimes distract me from previous ones; I have been obsessed with a certain idea or project for a short time but later lost interest; I often set a goal but later choose to pursue a different one; I finish whatever I begin, Setbacks don't discourage me; I am a hard worker; I have difficulty maintaining my focus on projects that take more than a few months to complete; I am diligent 
Leadteam

Scale: $1-4$
I can be a good leader; I am capable of being a good leader; I am seen as a capable leader; I like cooperating in a team; I cooperate well when working in a team; I am good at cooperating with team members.

The procedure adopted to compute the indices is to first recode all relevant questions are recoded to be positive outcomes, second, normalise all responses to z-scores (subtract mean and divide by SD) and third, take an average of the relevant z-scores across the questions that have no missing values. Questions follow Likert type scales ranging from 1 to 4 or 5 . 


\section{Sample used to investigate outcomes at age 15}

Our analysis for outcomes at age 15, pools round 1 data for the older cohort and round 3 data for the younger cohort so that sample size is increased as well as statistical power. We only consider children who had both parents alive at age 7-8. This gives us a sample of 2885 children. The data gathered seven years later when these children were 14-15 years of age, sees a fall in overall sample sizes by 3.4 per cent, due to sample attrition. However, attrition rates are higher if we only consider the older cohort from round 1 to round 5 (ages 7-8 to ages 21-22) at 18.6 per cent overall. Although still relatively low for a 15 year longitudinal study, we first looked at summary statistics to see if there was any systematic bias in the children who attrited in terms of individual and household characteristics at age 8 compared to those that remained in the sample. The characteristics considered were gender, age in months, region of residence, caregiver education, household wealth index, rural residence and household demographic composition. Online supplementary table A1 reports only results for selected variables such as gender and those where significant differences were found. It shows that children from wealthier households were more likely to attrite, probably due to migration. There are no significant differences pertaining to other characteristics. There were also no differences in terms of future orphanhood status if we consider the situation where only one parent died while the other remained alive until the child was 22 years old ${ }^{5}$. The table also shows that losing both parents between ages 8-22 is strongly associated with the

\footnotetext{
${ }^{5}$ In a previous investigation on orphans in Ethiopia based only on round 1, 2 and 3 data for the older cohort that was available at the time (Himaz, 2013), a child is assigned as being a paternal orphan if the father was reported to be alive in round 1 but was reported as being dead or there was no value recorded for this variable in rounds 2 or 3 . But in this investigation, with the benefit of having two more rounds of data, we update values for missing records in between rounds as appropriate and exclude from the investigation observations that report missing values.
} 
child dropping out of the survey implying that estimations that look at the effect of losing both parents are likely to be biased, under-estimating true effects. We therefore refrain from looking at the case of double orphans.

Table 2. Number of children with both parents alive versus single orphans at age 15

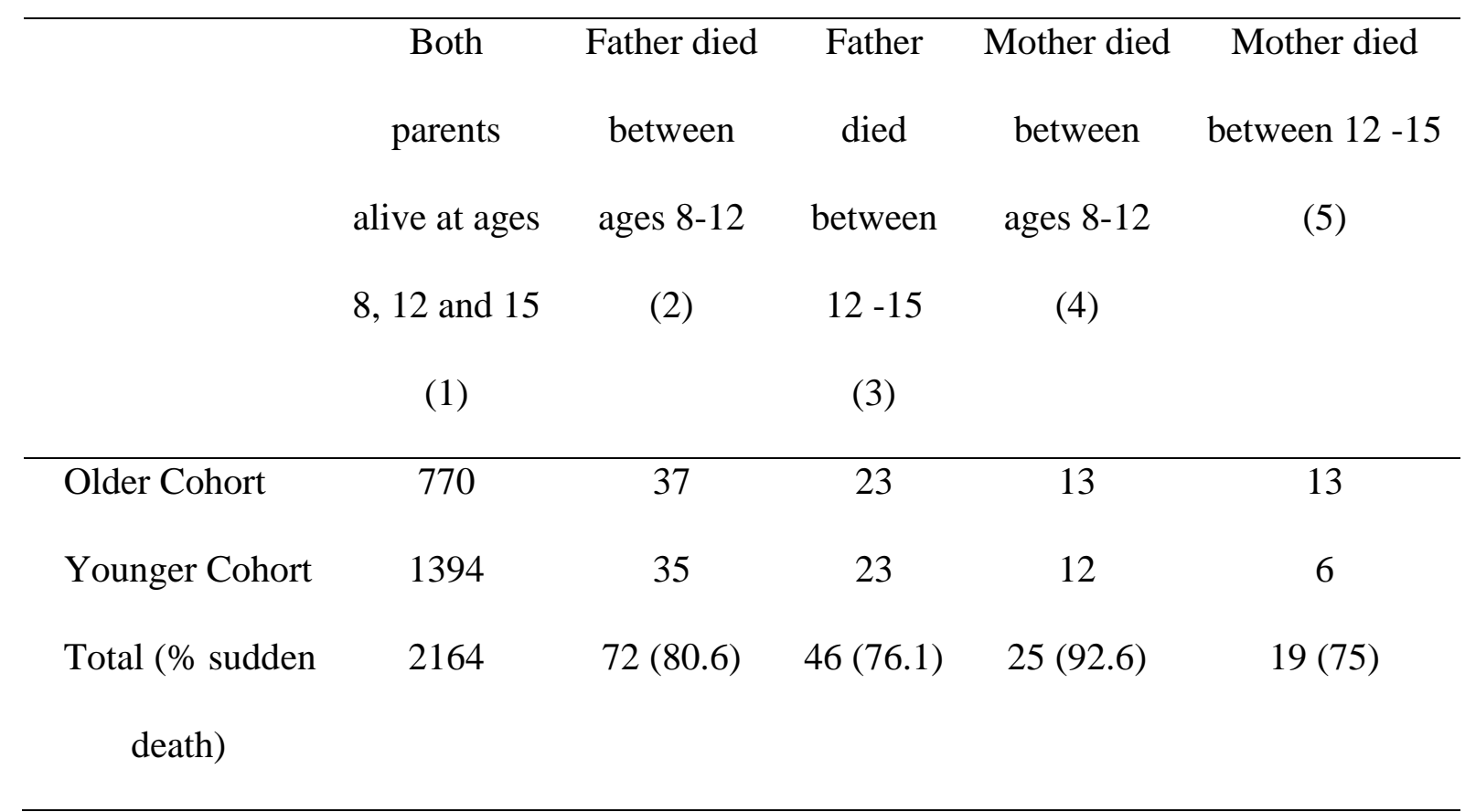

Values in columns 2 and 3 are compared to corresponding values in 1 (i.e., control group means). Pre-orphanhood characteristics are proportions unless otherwise stated.

Table 2 columns 1, 2 and 3 shows the number of orphans considered for the empirical analysis that looks at outcomes at age 15 , disaggregated by the period during a child's lifecourse that the father's death occurred. It also shows the number of children who lost a mother only, to illustrate the paucity in the number of observations which is another key reason why this paper focuses mainly on paternal death rather than maternal death. Moreover, we do not divide the group of paternal orphans by gender as small sample size can affect statistical power. The sample excludes children who had already lost a parent by the time 
they were 8 years old and double orphans. A further 1 per cent of the observations in the remaining sample is lost due to missing information on the wealth index ${ }^{6}$ at age 8 and/or non-cognitive outcomes at age $15^{7}$. Thus the total number of children who lost a father between the four years spanning ages 7-12 (but whose mother remained alive at age 15) is 72 with 73.5 per cent of these deaths assumed to be unanticipated or sudden. The survey does not record cause of death but a proxy for sudden death of the father is to see if father's illness has been recorded as a 'shock' the family experienced in the round of the survey where his death is also recorded ${ }^{8}$.

Table 3, panel A looks at pre-orphanhood characteristics at age 8 of non-orphans and those who lost the father between ages 7-12 or 12-15 while the remaining parent was alive at age 15 . The table shows that there are no statistically significantly differences at the 10 per cent level for any of the variables used apart from one of the region dummies. In order to investigate if unobservables could have affected orphans differently non-orphans, we regressed pre-orphanhood outcomes at age 8 on future orphan status (i.e., becoming a single orphan between ages 7-12 or 12-15), following Beegle et al. (2006) and Case and Ardington (2006). The significance of future orphan hood status will indicate that parental death influenced child outcomes even before the parent died or that there are unobservables correlated with parental death that cannot be controlled. The only available child-level non-

\footnotetext{
${ }^{6}$ See Briones (2017) for details on how the wealth index is calculated for Ethiopia using the Young Lives dataset.

${ }^{7}$ In more detail, 4 observations lost from the older cohort control group and 19 from the younger cohort control group. Note also that if details regarding a father's status (living at home, living away from home or dead) is missing for a particular round, data from other rounds are used to try and infer status. If details cannot be filled in the observation is excluded from the analysis.

${ }^{8}$ See discussion in footnote 3 regarding limitations of this proxy.
} 
cognitive measure at age 8 for both the younger and older cohort is subjective wellbeing. Unreported results show that future orphan status did not have a statistically significant impact on a child's subjective wellbeing at age 8 even when controlled for individual, household and caregiver characteristics, with standard errors clustered by community. It also had no impact on other outcomes at age 8 such as school enrolment, reading or writing ability. To address the possibility that pre-orphanhood characteristics closer to the time of being single-orphaned may be more relevant to children who were orphaned between ages 12-15, we regress outcomes at age 12 on future paternal orphanhood status of this group, together with other characteristics at age 12 . The results remain the same- future paternal orphan status is not significant for pre-orphanhood subjective wellbeing of child. It also has no impact on the subjective wellbeing of the caregiver, school enrolment or test scores.

Table 3 Panel B looks at non-cognitive outcomes at age 15 between paternal orphans and non-orphans. It shows that paternal orphans have lower subjective wellbeing than nonorphans. Moreover, those who lost a father in middle childhood between ages 7-12 have lower self-esteem at age 15 than their non-orphaned counter-parts. 
Table 3: Summary Statistics: Pre-orphanhood characteristics at age 8 (both cohorts) and outcomes at age 15

(1)

Panel A: Pre-orphanhood characteristics at age 8

Males

Caregiver is close relative

0.530

0.979

0.586

3.683

2.572

Mother's education (years)

Wealth index (range 0-1)

0.299

Household size (ln)

1.823

0.697

rural

Tigray

0.207

Oromia

Addis Ababa

Enrolled at school

0.205

0.122
(2)

(3)
0.556

0.957

0.597

3.444

2.153

0.288

1.816

0.639

$0.111^{*}$

0.236

0.111
0.587

0.953

0.522

2.261

3

0.302

1.878

0.630

0.152

0.152

0.217 
Coastal

Rayalaseema

Panel B: Outcomes at age 15

$-0.00570$

0.0344

$-0.118$

Self esteem

0.0135

$-0.160 *$

$-0.0318$

Subjective wellbeing

5.537

$4.486^{* * *}$

$5^{*}$

Observations

2164

72

46

Asterisks denote that the value in the cell is significantly different to corresponding value in control group with $* * * \mathrm{p}<0.01, * * \mathrm{p}<0.05, * \mathrm{p}<0$. 
Sample used to investigate outcomes at age 22

This sample consists only of the older cohort of children who were 22 years of age at the time of the fifth round of the Young Lives survey in 2016. Table 4, columns 1, 2, 3 and 4 shows the number of orphans and non-orphans considered in the empirical analysis, with the rest of the columns showing numbers of maternal orphans for illustrative purposes. As for the previous sample, when orphanhood is disaggregated by the gender of the parent, observations per group can be small. Therefore, we combine the adolescent groups that lost the father between 12-15 and 15-22 in the regressions to come ${ }^{9}$. Again, due to small sample size, maternal orphans are omitted from the empirical analysis to follow and paternal orphans are not further divided into groups by gender of child.

Table 4. Number of children with both parents alive versus single orphans at age 22 (Older Cohort only)

$\begin{array}{ccclccc}\text { Both } & \text { Father } & \text { Father } & \text { Father } & \text { Mother } & \text { Mother } & \text { Mother } \\ \text { parents } & \text { died } & \text { died } & \text { died } & \text { died } & \text { died } & \text { died } \\ \text { alive at } & \text { between } & \text { between } & \text { between } & \text { between } & \text { between } & \text { between } \\ \text { ages } 8, & \text { ages } 8 & 12 \text { and } & 15 \text { and } & \text { ages } 8 & \text { ages } 12 & 15 \text { and } \\ 12 \text { and } & \text { and } 12 & 15 & 22 & \text { and } 12 & \text { and } 15 & 22\end{array}$

15

\begin{tabular}{lccccccc}
\hline Observations & 588 & 30 & 17 & 38 & 8 & 7 & 20 \\
sudden & - & 73.5 & 58.8 & 90.7 & 84.2 & 93.3 & 97.3 \\
death $(\%)$ & & & & & & & \\
\hline
\end{tabular}

\footnotetext{
${ }^{9}$ As explained in the results section, this pooling becomes necessary to meet the balancing requirements of the treatment model in the IPWRA estimator.
} 
Table 5 panel A presents summary statistics for pre-orphanhood characteristics at age 8. There are no systematic differences significant at the 1 or 5 per cent level between orphans and non-orphans. Table 5 Panel B looks at how the means for these outcomes compare between orphans and non-orphans at age 22 . The non-cognitive outcomes such as peer-relationships, self-efficacy and self-esteem are significantly more favourable (higher) for orphans who lost the father later in adolescence compared to non-orphans.

As before, to see if unobservable characteristics associated with parental death influenced child non-cognitive outcomes even before the father died, we regress outcomes at age 8 on future orphanhood status ( i.e., a child will become orphaned between ages 7-12, $12-15$ or $15-22$ with both parents alive at age 22 being the omitted category) and other relevant control variables. Standard errors are clustered by community. The only noncognitive outcome at age 8 that the survey provides is subjective wellbeing and future orphanhood status has no effect on it. Nor does it have any effect on school enrolment status, reading or writing abilities ${ }^{10}$.

\footnotetext{
${ }^{10} \mathrm{We}$ also regress subjective wellbeing at age 12 for the child and caregiver and school enrolment on future orphanhood status (i.e., will become orphaned between ages 12-15 or 15-22 with both parents alive at age 22 omitted). Again, none of these outcomes are significant to orphanhood status. Finally, we regress non-cognitive outcomes such as agency, self-esteem and self-efficacy that all become available in round 3 data for the older cohort (when the child is 15) against becoming an orphan between 15-22 to find no significant impact.
} 
Table 5: Summary Statistics: Pre-orphanhood characteristics at age 8 and outcomes at age 22 (older cohort only)

Both parents alive

(1)
Father died 7-12

(2)
Father died 12-22

(3)

Panel A: Pre-Orphanhood characteristics at age 8

Males

0.528

0.467

0.611

enrolled at school

0.479

0.567

0.519

Wealth index (range 0-1)

0.211

0.225

0.246

Household size (ln)

1.841

1.735

1.924

Rural

0.700

Caregiver education (years)

1.835

3.330

1.981

0.218

0.191

0.216
$0.733 *$

2.033

4.033

2.133

$0.0667 *$

0.200

$0.367 *$
0.556

2.111

2.926

2.241

0.148

0.222

0.0926 
Panel B: Outcomes at age 22

\begin{tabular}{|c|c|c|c|}
\hline Agency & -0.00698 & 0.0510 & 0.169 \\
\hline Self efficacy & -0.0152 & -0.115 & $0.156^{*}$ \\
\hline Peer relationships & -0.0224 & -0.0568 & $0.203^{*}$ \\
\hline Leadership/teamwork & 0.00499 & -0.0458 & 0.0589 \\
\hline Grit & 0.0250 & -0.136 & 0.0448 \\
\hline Conscientiousness & 0.00470 & -0.0513 & 0.137 \\
\hline Self esteem & -0.0275 & 0.0646 & $0.198 *$ \\
\hline \multirow[t]{2}{*}{ Subjective wellbeing (scale 1-9) } & 5.426 & 5.667 & 5.204 \\
\hline & 587 & 30 & 54 \\
\hline
\end{tabular}

Asterisks denote that the value is significantly different to corresponding value in column (1), the control group, with $* * * \mathrm{p}<0.01, * * \mathrm{p}<0.05, *$ $\mathrm{p}<0$. Pre-orphanhood characteristics are proportions unless otherwise stated. Outcomes at 22 are standardized z-scores unless otherwise stated. 


\section{Empirical Strategy}

To estimate the causal effect of a father dying at different points in childhood on outcomes later in life, ideally outcomes for the same individual under different scenarios has to be compared. For example, outcomes when both parents are alive compared to outcomes for the same individual had the father died in middle childhood. But it is impossible for the same individual to be subject to both these situations (i.e., having both parents alive as well as having the father die). In the absence of experimental data, this missing counterfactual issue is addressed using the potential outcomes framework (Imbens \& Wooldridge, 2009). If we consider the case of a father dying (but the mother remains alive), then under the potential outcomes framework the 'treatment' $T$ that child $i$ is subject to can take multiple values depending on when in childhood the death occurs. A father could die when the child is between ages 8-12 (middle childhood; $T_{i}=1$ ), or between ages 12-15 (early adolescence; $\left.T_{i}=2\right)^{11}$. The case of both parents being alive (i.e., no treatment) is presented by $T_{i}=0$.

For each individual $i, i=1, \ldots, N$, in the sample, the triple $\left(Y_{i}, T_{i}, X_{i}\right)$ is observed. $Y_{i}$ is the outcome variable, $T_{i}$ is the multivalued treatment variable with $\mathrm{T} \in\{0,1,2\}$ and $X_{i}$ represents the vector of pre-treatment covariates. The indicator $D_{i t}\left(T_{i}\right)$ for receiving treatment $t$ for individual $i$ can be written as

$$
D_{i t}\left(T_{i}\right)=\left\{\begin{array}{l}
1, \text { if } T_{i}=t \\
0, \text { otherwise }
\end{array}\right.
$$

For each individual, there is a set of potential outcomes $\left(Y_{i 0}, Y_{i 1}, Y_{i 2}\right) . Y_{i t}$ denotes potential outcomes for each individual $i$ for $t \in\{0,1,2\}$. Only one of the potential outcomes is

\footnotetext{
${ }^{11}$ For the case that considers outcomes at age $22, T_{i}=2$ if death occurs ages between ages 12-22 (encompassing early, middle and late adolescence).
} 
observed depending on the treatment status. Adopting the potential outcomes framework pioneered by Rubin (1974), the observed outcome $Y_{i}$ can be written in terms of the treatment indicator $D_{i}\left(t_{i}\right)$ and the potential outcomes $Y_{i t}$ as

$$
Y_{i}=\sum_{t=0}^{2} D_{i t}\left(T_{i}\right) Y_{i t}
$$

If a father's death was random, the average effect of the treatment on the treated (ATT) is the average effect among those subjects that receive treatment level $\breve{t}$ of giving each subject treatment $\tilde{t}$ instead of treatment 0 :

$$
\operatorname{ATT}_{\tilde{t}, \breve{t}}=E\left\{\left(Y_{\tilde{t}}-Y_{0} \mid \mathrm{t}=\breve{t}\right)\right\}
$$

That is, $A T T_{\tilde{t}, \tilde{t}}$ is the mean effect for those who actually received treatment with $\tilde{t}$ defining the treatment level of the treated potential outcome, 0 being the treatment level of the control potential outcome and $\mathrm{t}=\breve{t}$ restricting the expectation to include those individuals who actually receive treatment level $\breve{t}$. The $A T T_{\tilde{t}, \breve{t}}$ is the parameter of interest in this paper rather than the average effect of giving each individual treatment $t$ instead of treatment 0 , ATE, expressed as $A T E_{t}=E\left(Y_{t}-Y_{0}\right)$. This is because ATTs and ATEs can differ when the treatment effects are not constant across individuals (i.e., there exists treatment effect heterogeneity) ${ }^{12}$.

\footnotetext{
${ }^{12}$ Thus our interest lies, for example, in comparing the effect of losing a father in middle childhood compared to the counterfactual of what the outcome would have been had both parents been alive, for those that lost the father in middle childhood. This is the ATT of losing the father in middle childhood. In contrast, the corresponding ATE compares the mean outcome had all the children in
} 
As the data do not come from a randomised experiment the ATT is estimated with additional conditioning on $X_{i}$ assumed to contain all characteristics associated with treatment assignment mechanism and potential outcomes so that the treatment is as good as randomly assigned. The key identifying assumption for the estimators we use is that the potential outcomes are independent of the treatment, given a set of observables X; that is, conditional independence (Heckman \& Robb, 1985) is met. More formally, $Y_{i t} \perp D_{i t}(T)_{i} \mid X_{i}, \forall_{t} \in$ $\{0,1,2\}$, where $\perp$ denotes independence. Apart from this the common support of overlap condition also needs to be satisfied that requires each child to have a positive probability of receiving each treatment level (Imbens \& Wooldridge, 2009). Formally for each possible X in the population and each treatment level, $0<\operatorname{Pr}\left[T_{i}=t \mid X_{i}=x\right], \forall_{t} \in\{0,1,2\}$ and $\forall_{x}$ in support of X. Finally, the standard independent and identically distributed (i.i.d) sampling assumption is also required that implies the potential outcomes and treatment status of each individual is unrelated to the potential outcomes and treatment status of other individuals in the population (Wooldridge, 2010). Under these assumptions, the conditional expectation of potential outcome for treatment level t identified by conditional expectations of observed outcomes of individuals receiving treatment $t$ :

$$
E\left[Y_{i t} \mid X_{i}\right]=E\left[Y_{i t} \mid D_{i t}\left(T_{i}\right), X_{i}\right]=E\left[Y_{i} \mid T_{i}, X_{i}\right]
$$

The unconditional means can be estimated by averaging the conditional means. In the case of multivalued treatments, a practical alternative to conditioning directly on a large number of $X_{i}$ is to use a generalised propensity score (GPS) as proposed by Imbens (2000). The GPS is defined as the conditional probability of receiving a particular level of treatment our study lost the father in middle childhood with the mean outcome had all of them had both parents alive 
given pre-treatment variables such that $r(t, x) \equiv \operatorname{Pr}\left[T_{i}=t \mid X_{i}=x\right]=E\left[D_{i t}\left(T_{i}\right) \mid X_{i}=x\right]$. Potential outcome means can be calculated by weighting the observed outcome by the inverse of the conditional probability of the received treatment:

$$
E\left[\frac{Y_{i} D_{i t}\left(T_{i}\right)}{r\left(t, X_{i}\right)}\right]=E\left[Y_{i t}\right]
$$

To estimate the ATTs we use an estimator that combines regression adjustment and propensity score methods - inverse probability weighting with regression adjustment (IPWRA) as described in (Cattaneo, 2010; Wooldridge, 2010). Conceptually, in the first step, the following 'treatment model' is estimated using multinomial logit:

$$
k_{i}=\gamma x_{i}^{\prime}+\tau
$$

where $k$ is the treatment status of individual i at age 15 (or age 22) with $k=0$ if both parents are alive, $k=1$ if father died between ages 8-12 and $k=2$ if father died between 12-15 (or 12-22 if considering outcomes at age 22). $x^{\prime}$ is a vector of pre-orphanhood characteristics at age 8 containing education level of the child's father, household wealth index, rural residence (urban omitted), and the region of residence (Tigray, Amhara, Oromo and Addis Ababa with Southern Nations, Nationalities and people's region omitted) and $\tau$ is the unobserved error term. The parameters of this estimation are used to predict the GPS - the conditional probability of receiving a particular level of treatment given pre-treatment variables. The inverse of the GPS computed as $\frac{D_{i t}\left(T_{i}\right)}{\hat{r}\left(t, X_{i}\right)}$ are used to weight observations for each level of treatment. The weights will be large when the probability of getting treatment is small. Thus 
observations that are not likely to contain missing data get a weight close to one; observations that are likely to contain missing data get a weight larger than one, potentially much larger ${ }^{13}$. In the second step, the 'outcome model' is estimated for each treatment level separately using regression weighted by the inverse probability of treatment (i.e., the inverse of the GPS):

$$
y_{i t}=\beta_{0 t}+\beta_{1 t} x_{i}^{\prime \prime}+\varepsilon_{t}, \quad \forall_{t} \in\{0,1,2\}
$$

where $y$ is the non-cognitive outcome (such as subjective wellbeing) at age 15 (or 22) for child $i$ receiving treatment level $t, x^{\prime \prime}$ is a vector of pre-orphanhood characteristics at age 8 comprising gender of child, age in months, school enrolment status, the log of household size, the education level of the caregiver, household wealth, region of residence and a dummy indicating rural residence. The unobservable error term is $\varepsilon$. The estimated coefficients from this weighted regression are used to obtain treatment specific predicted outcomes for each individual. Then the ATT is estimated as the average of the difference of predicted values for $Y_{\tilde{t}}$ and $Y_{0}$ over the subsample of treated units. The estimation procedure can be rewritten as a one-step step estimation within a Generalised Method of Moments (GMM) framework. A

\footnotetext{
${ }^{13}$ The rationale for weighting is that samples receiving the different treatments may differ in their distributions of pre-treatment variables and, therefore, possibly differ in terms of their observed outcomes in ways that are not attributable to the treatment. If all the variables with pre-treatment differences are observed and that the groups have at least some members with similar covariates (i.e., the conditions of conditional independence and overlap hold), then in principle, a treatment sample can be reweighted to make the distribution of covariates match that of any of the other treatment groups (Kang \& Schafer, 2007; Rosenbaum \& Rubin, 1983).
} 
key advantage here is that the standard errors automatically account for the estimation error from estimated propensity scores ${ }^{14}$.

The estimator is 'doubly robust' as it is sufficient that either the outcome model or treatment model is specified correctly to consistently estimate treatment effects (Wooldridge 2010: 930-933)

The results of the IPWRA are compared with results of the Ordinary Least Squares estimator which is an alternative that is not based on the potential outcomes framework. The model estimated is:

$$
y_{i}=\alpha+\sum_{j=0}^{2} \delta_{j} d_{i j}+\beta x_{i}^{\prime \prime}+\varepsilon
$$

\footnotetext{
${ }^{14}$ The estimations in the next sections are performed using the teffects command in the statistical package Stata.
}

${ }^{15}$ Using simply the regression adjustment estimator instead of the IPWRA estimator would involve regressing the outcome on $x^{\prime \prime}$ for each treatment level, after which the predicted outcomes for each individual and treatment level are computed using data only from the individuals receiving the relevant treatment level. Potential outcomes means are estimated using the average of these predicted values. These potential outcomes can then be contrasted to estimate treatment effects. Drawbacks of this technique include biases arising out of miss-specifying the outcome model and the investigator not being able to directly assess the covariate balance between treatment groups. The weighting estimator we use directly addresses the latter issue. However, a drawback with the inverse probability weighting estimators especially with small sample sizes is that they become extremely unstable as the overlap assumption gets close to being violated even if the functional form for the treatment model is correctly specified. None of the estimations in this paper faced the issue of the overlap condition being violated and this was robust to changes in specification. 
where $y$ is the non-cognitive outcome for individual $i$ at age 15 (or age 22 as relevant), $\boldsymbol{x}^{\prime \prime}$ is a vector of pre-orphaned characteristics at age 8 as described in the outcome model above and $d$ is a categorical dummy for treatment status: $j=1$ if father died between ages 8-12 and 0 otherwise and $j=2$ if father died between 12-15 (or 12-22 if considering outcomes at age 22) and 0 otherwise with both parents alive $(j=0)$ being the baseline category. The coefficients $\delta$ may provide good summary statistics of the effect of the treatment but there are caveats associate with the use of OLS for estimating causal effects as opposed to using it for prediction. The OLS estimation relies on conditional independence in combination with functional form assumptions. The indicators for treatment and the covariates enter additively and linearly. The method works well when the covariate distributions do not differ substantially by treatment status and conditional expectations are linear. If these conditions do not hold, the estimations can be sensitive to minor changes in the specification because of their heavy reliance on extrapolation (Imbens, 2015). Moreover, when treatment heterogeneity is empirically important, the OLS estimates for average effects lie between the effect on the treated and the controlled i.e., between ATT and the average effect on the controls $A T C_{\tilde{t}, 0}=E\left\{\left(Y_{\tilde{t}}-Y_{0} \mid \mathrm{t}=0\right)\right\}$. The value is closer to ATC the lower is the proportion of control units and closer to ATT the lower is the proportion of treatment units (Słoczyński, 2015). Given the caveats associated with the use of OLS we choose the IPWRA estimator that is based on a framework allowing causal inference, to provide the baseline results in this paper. Moreover, the IPWRA estimator is 'doubly robust', as discussed previously. However, we compare the IPWRA results with OLS results both as a check that calculations were carried out correctly and to ensure that we can understand what is driving any difference between the estimates, if they are different. 


\section{Results}

\section{Outcomes at age 15}

The results in this section look first at how outcomes at age 15 were affected by paternal death using the IPWRA estimator. Only the results pertaining to the ATT is reported in Table 6 , rather than the coefficients of the treatment and outcomes models as well, in the interest of space and clarity. As the table shows, losing a father in middle childhood between ages 7-12 has a significantly negative effect on an orphan's sense self-esteem and subjective wellbeing at age 15 . Thus, their self-esteem falls by 0.15 standard deviations while their subjective wellbeing falls by 0.9 units on a scale that goes from 0 to 9 . This works out as a 9.4 per cent fall in self-esteem and a 16 per cent fall in subjective wellbeing compared to their respective potential outcomes, had not the father died ${ }^{16}$. Losing a father in early adolescence does not have a statistically significant effect on any of the outcomes investigated.

In order to investigate the robustness of these results we looked at whether the covariates were balanced at the various levels of treatment. Online supplementary table A2 provides the covariate balance summary. The table shows that the weighted standardised differences are all reasonably close to zero and that the weighted variance ratios are close to

\footnotetext{
${ }^{16}$ The figures are calculated as follows: Self-esteem at age 15 for this group is -0.16 as reported in Table 3 Panel B. Since ATT is -0.15 , the potential self-esteem is -.01 . Since self-esteem is assumed to follow a standard normal distribution, the area under $Z=-0.01$ is approximately $49.46 \%$ and when $\mathrm{Z}=-0.16$ the area is $44.8 \%$ Thus the actual outcome compared to the potential outcome is (44.849.46)/49.46=9.7\% . Similarly, at age 15 the actual subjective wellbeing of children orphaned in middle childhood is 4.486 . The estimated ATT is -0.9 . Thus the subjective wellbeing without father's death would be $4.486+0.9=5.386$. Then the fall in subjective wellbeing is $0.9 / 5.386 \sim 16 \%$.
} 
one. Thus the treatment model seems to balance the covariates ${ }^{17}$. The IPWRA results are closely supported by those of the alternative estimator, OLS, reported in online supplementary table A3. Again the loss of the father in middle childhood reduces self-esteem by 0.15 standard deviations and subjective wellbeing of the paternal orphans falls by 0.89 units. Losing a father in early adolescence also reduces subjective wellbeing by 0.34 units, significant at the 10 per cent level. The OLS results also show that household wealth and father's education exert a positive influence on self-esteem, raising it by 0.58 and 0.01 standard deviations; Wealth, rural residence, household size, rural residence and mother's education exert a positive influence on subjective wellbeing at 15 raising it by $2.08,0.37$, 0.89 and 0.05 , respectively.

Table 6: ATT on outcomes at age 15 conditioned on characteristics at age 8 Agency Self Esteem Subjective wellbeing

\begin{tabular}{lccc}
\hline Father died between 7-12 & 0.04 & $-0.15^{*}$ & $-0.90^{* * * *}$ \\
vs. both alive & $(0.069)$ & $(0.08)$ & $(0.205)$ \\
Father died between 12-15 & -0.11 & 0.02 & -0.3 \\
vs. both alive & $(0.076)$ & $(0.095)$ & $(0.227)$ \\
Observations & 2,282 & 2,282 & 2,282
\end{tabular}

Note: Only ATT reported. The results based on IPWRA estimations where outcome model includes the following characteristics at age 8: gender, age, school enrolment status, caregiver education, region of residence, rural residence, wealth index, log of household size; treatment model includes father's education, wealth index, rural residence and region of residence. Standard errors in parentheses. $* * * \mathrm{p}<0.01, * * \mathrm{p}<0.05, * \mathrm{p}<0.1$

\footnotetext{
${ }^{17}$ Unfortunately we cannot perform a formal test on balance for multivalued treatment effects as this is not implemented in STATA, the statistical package used.
} 


\section{Outcomes at age 22}

Do the negative effects of losing a father in middle childhood and adolescence persist to age 22? Table 7, columns 1, 2 and 3 report results for agency, self-esteem and subjective wellbeing, measured on a scale comparable to the scale used when the child was 15 . The rest of the columns report results for instruments that were measured only at age 22 . The results show that paternal death in middle childhood did not have a persistent effect on any of the non-cognitive outcomes reported. In contrast, the loss of the father in adolescence had a significant positive impact on various non-cognitive outcomes in our sample. Thus agency, self-efficacy, self-esteem and peer relationships all increased by $0.31,0.31,0.28$ and 0.26 standard deviations, respectively. Again to investigate robustness of results we look for balance in covariates at the two levels of treatment. Online supplementary table A4 provides the covariate balance summary. OLS estimation results reported in Online supplementary table A5a strongly support the IPWRA estimations for ATT discussed above, showing that agency, self-efficacy and peer-relationships are all positively influenced by a father's death during a child's adolescent years, although the impact is slightly smaller at $0.11,0.13$ and 0.21 standard deviations, respectively. These results are driven mainly by those whose father died later in adolescence aged 15-22, as seen in OLS estimations that disaggregates the adolescent cohort as those aged 12-15 and 15-22 (Table A5b). The OLS results also show that gender has a strong influence on several non-cognitive outcomes at age 22. Being male significantly positively influences agency, peer relationships, leadership and teamwork, grit, conscientiousness and self-efficacy, with impact ranging from 0.07 to 0.18 standard deviations. Wealth influences positively self-esteem (0.71 standard deviations) and subjective wellbeing (1.79 units) but has a negative impact on grit ( 0.38 standard deviations). School enrolment at age 8 positively influences agency, conscientiousness and grit at age 22 . 
It should be recapitulated here that the results, particularly those regarding outcomes at age 22 are based on a small treatment group ( 55 children who lost the father between ages 12 and 22, as indicated in Table 4). While a larger treatment group could have facilitated the investigation of heterogeneous treatment effects (for example are girls' outcomes as a consequence of father's death significantly differently to boys') and the inability to do so is a limitation of this study, a larger treatment group would not get rid of problems affecting causal inference such as sample selection bias. To address the latter more effectively, additional information will be needed on the cause of father's death, father's age at birth for the full sample, and information on unobservables such as attitudes to risk and habits such as alcohol and drug intake that may all have an impact on child non-cognitive outcomes. Thus a larger treatment group on its own would not have improved results. 
Table 7: ATT on outcomes at age 22 conditioned on characteristics at age 8

\begin{tabular}{|c|c|c|c|c|c|c|c|c|}
\hline & Agency & $\begin{array}{c}\text { Self } \\
\text { Esteem }\end{array}$ & $\begin{array}{l}\text { Subjective } \\
\text { wellbeing }\end{array}$ & $\begin{array}{c}\text { Peer } \\
\text { relationshi } \\
\text { ps }\end{array}$ & $\begin{array}{c}\text { Lead/Tea } \\
\text { m. }\end{array}$ & Grit & Consc. & $\begin{array}{c}\text { Self } \\
\text { Efficacy }\end{array}$ \\
\hline $\begin{array}{l}\text { Father died } \\
\text { between } 7-12 \text { vs }\end{array}$ & 0.09 & 0.08 & 0.23 & 0.01 & -0.04 & -0.11 & -0.04 & 0.09 \\
\hline both alive & $(0.105)$ & $(0.139)$ & $(0.306)$ & $(0.091)$ & $(0.121)$ & $(0.085)$ & $(0.081)$ & $(0.105)$ \\
\hline Father between & $0.31 * *$ & $0.31 * *$ & 0.47 & $0.26^{* *}$ & 0.09 & -0.04 & 0.15 & $0.28^{* *}$ \\
\hline $12-22$ vs. both & & & & & & & & \\
\hline alive & $(0.145)$ & $(0.139)$ & $(0.39)$ & $(0.11)$ & $(0.099)$ & $(0.096)$ & $(0.116)$ & $(0.121)$ \\
\hline Observations & 672 & & 671 & 672 & 672 & 672 & 672 & 672 \\
\hline
\end{tabular}

Note: Only ATEs reported. The results based on IPWRA estimations where outcome model includes the following characteristics at age 8: gender, age, school enrolment status, caregiver education, region of residence, rural residence, wealth index, log of household size; treatment model includes father's education, wealth index, rural residence, region of residence. Only older cohort data are used. Standard errors in parentheses $* * * \mathrm{p}<0.01, * * \mathrm{p}<0.05, * \mathrm{p}<0.1$ 
Table 8: Context at age 15

\section{Both cohorts}

Older cohort only

\begin{tabular}{|c|c|c|c|c|c|c|}
\hline & $\begin{array}{l}\text { Both parents } \\
\text { alive }\end{array}$ & $\begin{array}{l}\text { Father died 7- } \\
12\end{array}$ & $\begin{array}{l}\text { Father died 12- } \\
15\end{array}$ & $\begin{array}{l}\text { Both parents } \\
\text { alive }\end{array}$ & $\begin{array}{l}\text { Father died 7- } \\
12\end{array}$ & $\begin{array}{l}\text { Father died 12- } \\
15\end{array}$ \\
\hline $\begin{array}{l}\text { Close relative is main } \\
\text { caregiver (age } 15 \text { ) }\end{array}$ & 0.964 & 0.956 & 0.952 & 0.951 & 0.939 & 0.947 \\
\hline Household Wealth age 15 & 0.396 & 0.379 & 0.382 & 0.366 & 0.349 & 0.326 \\
\hline School enrolment- age 15 & 0.914 & 0.882 & 0.952 & 0.908 & 0.818 & 0.895 \\
\hline $\begin{array}{l}\text { Caregiver's subjective } \\
\text { wellbeing* }\end{array}$ & 5.009 & $4.176^{* * *}$ & $4.381 *$ & 4.434 & $3.697 * *$ & 3.842 \\
\hline $\begin{array}{l}\text { Caregiver's expected } \\
\text { subjective wellbeing } 4 \text { year } \\
\text { from now* }\end{array}$ & 6.523 & $5.824 * * *$ & 6.119 & 6.258 & $5.636^{*}$ & 5.842 \\
\hline Paid work (hours) & 0.271 & $0.618^{*}$ & 0.119 & 0.374 & $1.091^{*}$ & 0.158 \\
\hline Unpaid work (hours) & 1.644 & 1.618 & 1.381 & 1.436 & 1.758 & 1.895 \\
\hline
\end{tabular}




\begin{tabular}{|c|c|c|c|c|c|c|}
\hline Household chores (hours) & 1.644 & 1.618 & 1.381 & 2.510 & 2.333 & 1.895 \\
\hline Observations & 2096 & 68 & 42 & 698 & 33 & \\
\hline
\end{tabular}

Table 9: Context at age 22

\begin{tabular}{llll}
\hline & Both parents alive & Father died 7-12 & Father died 12-22 \\
\hline Household wealth & 0.457 & $0.391^{*}$ & 0.473 \\
Married/cohabiting & 0.190 & 0.267 & 0.185 \\
Enrolled in education & 0.366 & 0.433 & 0.352 \\
Household chores (hours) & 2.068 & 2.333 & 1.889 \\
Unpaid work (hours) & 2.180 & 2.500 & 1.944 \\
Paid work (hours) & 2.769 & 1.767 & 3.444 \\
Consumes alcohol at least & 0.185 & 0.200 & 0.241 \\
once a week & & & \\
\hline
\end{tabular}




\section{Discussion}

What can explain the above results that paternal death was not associated with negative outcomes? Part of the reason may lie in how the developmental context changed for the children following the father's death. Table 8 shows that for those orphaned between ages 7 and 12, the main caregiver remained the mother, grandparent or sibling (nearly 94 per cent of the orphans compared to 96 percent of non-orphans), and although caregiver subjective wellbeing and optimism regarding the future were significantly lower than those for caregivers of non-orphans, and orphans engaged more in paid work, there were no differences household wealth or school enrolment at age 15 . The context for those who were orphaned between ages 12-15 does not significantly defer from that for non-orphans across any of the characteristics we consider apart from caregiver subjective wellbeing. At age 22, there are few household characteristics and outcomes that are significantly different between the groups. Although those who lost the father live in significantly poorer households at age 22 , this has not affected school enrolment, marriage, hours worked or any of the other outcomes reported (Table 9). Thus for those who lost the father in middle-childhood, relative stability in context may have mitigated the persistence of negative outcomes in the longer term. As several studies note that with suitable care-giver arrangements (Abebe and Aase 2007) and 'protective factors' such as 'family provision, quality of care and economic assistance' outcomes for orphans are not inevitably negative (Sherr et al. 2008:535). But can this alone explain the rather surprising result that paternal death during a child's adolescence correlated with significantly positive non-cognitive outcomes as a young adult? The positive adaptive behaviour displayed by the orphans in our sample seems to be related to the time during their life course that the father died: Adolescence. As discussed earlier in this article, adolescence is a period when outward orientation, the seeking for autonomy and risk taking is high and in the case of the orphans in our sample the 'perfect storm' created by adolescence 
together with relatively stable developmental contexts, societal norms that foster household interdependency and responsibility-taking behaviour among children in the face of adversity (Boyden, 2009) may have supported positive adaptive behaviour. Qualitative evidence based on previous studies on the orphans from the Young Lives Ethiopia survey seems to support this contention. For example, Crivello and Chuta (2012, p. 544) discuss how Bereket, a 15 year old orphan who works in a garage after school washing cars and fitting tyres to supplement household income has used the opportunity to learnt to drive, and is proud of taking more risks than his peers: 'I take risks to learn new things...I still have some friends who don't know how to drive because they don't take risks'. Camfield (2011) provides qualitative evidence from interviews with three 15 year old orphans from the same cohort (al be it double orphans) who express feelings of authority over important decisions in their life, are driven and ambitious and are seen to be more resilient than peers by their caregivers. Even when a sense of vulnerability arises with regard to living in a household with only one adult wage earner, it goes towards influencing the behaviour of one orphan to spend time with other children who behave well and attend school, 'for fear that they might be disliked or condemned by the people around here', which would make them more vulnerable if the caregiver died. The positive adaptive behaviour of the adolescents can also be related to how children make sense of the death of their father and how this may shape the development of personality. Crivello and Chuha note that the orphans view death as natural and irrevocable 'You know, we all are created to die. So, I don't have to remember him all my life since I myself will die one day'. This can create a mindset that promotes resilience resulting in positive behaviour that seeks new strategies, greater effort, or solving conflicts peacefully in the face of adversity rather than negative behaviour that results in helplessness, giving up, cheating, or aggressive retaliation (Yeager \& Dweck, 2012). 


\section{Conclusions}

This paper compared outcomes at ages 15 and 22 for children that lost only the father in middle childhood or adolescence based on ATT estimated using a multi-valued treatment effects framework. The results are compared to that of an alternative estimator, OLS that conditioned outcomes at ages 15 and 22 on pre-orphanhood characteristics at age 8 . The key finding was that the time in a child's life course during which the father dies matters significantly to non-cognitive outcomes at age 22 . Thus the loss of a father in middle childhood and early adolescence has significant negative impacts on non-cognitive outcomes at age 15 reducing an orphan's self-esteem significantly by 0.15 standard deviations and subjective wellbeing by 16 per cent. But these effects are not persistent. Instead, the loss of the father between ages 12-22, encompassing early, middle and late adolescence have significant positive effects on agency, self-efficacy, self-esteem and peer relationships as a young adult aged 22 , improving them by $0.31,0.28,0.31$ and 0.26 standard deviations respectively. These results are driven mainly by the older orphans in the $15-22$ category. These orphans have a more positive self-conception of relationships with peers, of their involvement in household decision making, ability to cope with daily hassles as well as adaptation after experiencing all kinds of stressful life events. This suggests positive adaptive behavior after the death of the father that may have been the result of the interactions of two key factors. The first is developmental contexts that do not seem to have been disrupted drastically, with caregiver continuing to be the mother or close relative and household wealth, enrolment in education and time use not differing significantly between orphans and nonorphans. This supportive context is set within the wider Ethiopian social context where a sense of respect and obligation structures children's roles and their responsibilities towards their households. This context fused with paternal death occurring during adolescence -a period of rapid change with simultaneous and sudden increases in hormonal, neural and 
social change, when children become more autonomous, turn to peers for support and take more risk- seems to have resulted in positive adaptive behavior. This is confirmed by qualitative evidence based on studies on the Ethiopian orphans belonging to the same cohort as the orphans used in this article, showing orphans to be driven and ambitious, to express more authority over decisions in their lives and be seen to be more resilient than peers by their caregivers. It remains to be seen how the positive non-cognitive impacts manifest in terms of productivity, wages, opportunities and welfare of these individuals. 
References

Abebe, T., \& Aase, A. (2007). Children, AIDS and the politics of orphan care in Ethiopia: The extended family revisited. Social Science \& Medicine, 64(10), 2058-2069. doi:10.1016/j.socscimed.2007.02.004

Ainsworth, M., Beegle, K., \& Koda, G. (2005). The impact of adult mortality and parental deaths on primary schooling in north-western Tanzania. Journal of Development Studies, 41(3), 412-439. doi:10.1080/0022038042000313318

Apostolou, M. (2010). Sexual selection under parental choice in agropastoral societies. Evolution and Human Behavior, 31(1), 39-47. doi:10.1016/j.evolhumbehav.2009.06.010

Beegle, K., De Weerdt, J., \& Dercon, S. (2009). The intergenerational impact of the African orphans crisis: a cohort study from an HIV/AIDS affected area. International Journal of Epidemiology, 38(2), 561-568. doi:10.1093/ije/dyn197

Beegle, K., DeWeerdt, J., \& Dercon, S. (2006). Orphanhood and the long-run impact on children. American Journal of Agricultural Economics, 88(5), 1266-1272. doi:10.1111/j.1467-8276.2006.00943.x

Beegle, K., \& Krutikova, S. (2008). Adult mortality and children's transition into marriage. Demographic Research, 19, 1551-1573. doi:10.4054/DemRes.2008.19.42

Blakemore, S.-J., \& Mills, K. L. (2014). Is Adolescence a Sensitive Period for Sociocultural Processing? Annual Review of Psychology, Vol 65, 65, 187-207. doi:10.1146/annurevpsych-010213-115202

Borghans, L., Duckworth, A. L., Heckman, J. J., \& Weel, B. t. (2008). The Economics and Psychology of Personality Traits. Journal of Human Resources, University of Wisconsin Press, 43.

Boyden, J. (2009). Risk and Capability in the Context of Adversity: Children's Contributions to Household Livelihoods in Ethiopia Children. Youth and Environments, 19, 26.

Briones, K. (2017). How many rooms are there in your house? Constructing the Young Lives Wealth Index . In: Technical note 43, Young Lives.

Brown, B. B. (2004). Adolescents' relationships with peers. Hoboken, NJ: Wiley.

Camfield, L. (2011). Outcomes of Orphanhood in Ethiopia: A Mixed Methods Study. Social Indicators Research, 104(1), 87-102. doi:10.1007/s11205-010-9728-y

Cantril, H. (1965). The Pattern of Human Concern . In. New Brunswick, NJ: Rutgers University Press.

Capaldi, D. M., Dishion, T. J., Stoolmiller, M., \& Yoerger, K. (2001). Aggression toward female partners by at-risk young men: The contribution of male adolescent friendships. Developmental Psychology, 37(1), 61-73. doi:10.1037//0012-1649.37.1.61

Cas, A. G., Frankenberg, E., Suriastini, W., \& Thomas, D. (2014). The Impact of Parental Death on Child Well-being: Evidence From the Indian Ocean Tsunami. Demography, 51(2), 437-457. doi:10.1007/s13524-014-0279-8

Case, A., \& Ardington, C. (2006). The impact of parental death on school outcomes: Longitudinal evidence from South Africa. Demography, 43(3), 401-420. doi:10.1353/dem.2006.0022

Cattaneo, M. D. (2010). Efficient semiparametric estimation of multi-valued treatment effects under ignorability. Journal of Econometrics, 155(2), 138-154. doi:10.1016/j.jeconom.2009.09.023 
Chen, S. H., Chen, Y.-C., \& Liu, J.-T. (2009). The Impact of Unexpected Maternal Death on Education: First Evidence from Three National Administrative Data Links. American Economic Review, 99(2), 149-153. doi:10.1257/aer.99.2.149

Crivello, G., \& Chuta, N. (2012). Rethinking orphanhood and vulnerability in Ethiopia. . Development in Practice, 22, 12.

Duckworth, A. L., \& Quinn, P. D. (2009). Development and Validation of the Short Grit Scale (Grit-S). Journal of Personality Assessment, 91(2), 166-174. doi:10.1080/00223890802634290

Eccles, J. S., Midgley, C., Wigfield, A., Buchanan, C. M., Reuman, D., Flanagan, C., \& Maciver, D. (1993). DEVELOPMENT DURING ADOLESCENCE - THE IMPACT OF STAGEENVIRONMENT FIT ON YOUNG ADOLESCENTS EXPERIENCES IN SCHOOLS AND IN FAMILIES. American Psychologist, 48(2), 90-101. doi:10.1037/0003-066x.48.2.90

Evans, D. K., \& Miguel, E. (2007). Orphans and schooling in Africa: A longitudinal analysis. Demography, 44(1), 35-57. doi:10.1353/dem.2007.0002

Feinstein, L., \& Bynner, J. (2004). The importance of cognitive development in middle childhood for adulthood socioeconomic status, mental health, and problem behavior. Child Development, 75(5), 1329-1339. doi:10.1111/j.14678624.2004.00743.x

Gimenez, L., Chou, S. Y., Liu, J. T., \& Liu, J. L. (2013). Parental Loss and Children's Well-Being. Journal of Human Resources, 48(4), 1035-1071.

Gore, S., \& Eckenrode, J. (1996). Context and process in research on risk and resilience. In R. J. Haggerty, L. K. Sherrod, N. Garmezy, \& M. Rutter (Eds.), Stress, Risk, and Resilience in Children and Adolescents: Processes, Mechanisms and Interventions (pp. 19-40). Cambridge: Cambridge University Press.

Grigorenko, E. L. (2017). Brain Development: The Effect of Interventions on Children and Adolescents. . Disease Control Priorities (Volume 8): Child and Adolescent Health and Development, 13.

Heckman, J. J., \& Kautz, T. (2012). Hard evidence on soft skills. Labour Economics, 19(4), 451464. doi:10.1016/j.labeco.2012.05.014

Heckman, J. J., \& Robb, R. (1985). ALTERNATIVE METHODS FOR EVALUATING THE IMPACT OF INTERVENTIONS - AN OVERVIEW. Journal of Econometrics, 30(1-2), 239-267. doi:10.1016/0304-4076(85)90139-3

Heissler, K., \& Porter, C. (2013). Know Your Place: Ethiopian Children's Contributions to the Household Economy. European Journal of Development Research, 25(4), 600-620. doi:10.1057/ejdr.2013.22

Himaz, R. (2013). Impact of Parental Death in Middle Childhood and Adolescence on Child Outcomes. Journal of African Economies, 22(3), 463-490. doi:10.1093/jae/ejt001

Imbens, G. W. (2000). The role of the propensity score in estimating dose-response functions. Biometrika, 87(3), 706-710. doi:10.1093/biomet/87.3.706

Imbens, G. W. (2015). Matching Methods in Practice Three Examples. Journal of Human Resources, 50(2), 373-419. doi:10.3368/jhr.50.2.373

Imbens, G. W., \& Wooldridge, J. M. (2009). Recent Developments in the Econometrics of Program Evaluation. Journal of Economic Literature, 47(1), 5-86. doi:10.1257/jel.47.1.5

Kang, J. D. Y., \& Schafer, J. L. (2007). Demystifying double robustness: A comparison of alternative strategies for estimating a population mean from incomplete data. Statistical Science, 22(4), 523-539. doi:10.1214/07-sts227 
King, R. B., \& Watkins, D. A. (2012). Cross-Cultural Validation of the Five-Factor Structure of Social Goals: A Filipino Investigation. Journal of Psychoeducational Assessment, 30(2), 181-193. doi:10.1177/0734282911412542

Marsh, H. W., \& Oneill, R. (1984). SELF DESCRIPTION QUESTIONNAIRE .3. THE CONSTRUCTVALIDITY OF MULTIDIMENSIONAL SELF-CONCEPT RATINGS BY LATE ADOLESCENTS. Journal of Educational Measurement, 21(2), 153-174. doi:10.1111/j.17453984.1984.tb00227.x

Masten, A. S. (2001). Ordinary magic - Resilience processes in development. American Psychologist, 56(3), 227-238. doi:10.1037/0003-066x.56.3.227

Nelson, E. E., Jarcho, J. M., \& Guyer, A. E. (2016). Social re-orientation and brain development: An expanded and updated view. Developmental Cognitive Neuroscience, 17, 118-127. doi:10.1016/j.dcn.2015.12.008

Nelson, E. E., Leibenluft, E., McClure, E. B., \& Pine, D. S. (2005). The social re-orientation of adolescence: a neuroscience perspective on the process and its relation to psychopathology. Psychological Medicine, 35(2), 163-174. doi:10.1017/s0033291704003915

Outes-Leon, I., \& Dercon, S. (2008). Survey attrition and attrition bias in Young Lives In: Technical Note 5, Young Lives.

Papalia, D. E., Olds, S. W., \& Feldman, R. D. (2007). Human Development: McGraw Hill.

Richards, G. E., Ellis, L. A., \& Neill, J. T. (2002). The ROPELOC: Review of Personal Effectiveness and Locus of Control: A comprehensive instrument for reviewing life control. Paper presented at the Self-Concept Research: Driving International Research Agendas, 6-8 August, Sydney.

Rosenbaum, P. R., \& Rubin, D. B. (1983). THE CENTRAL ROLE OF THE PROPENSITY SCORE IN OBSERVATIONAL STUDIES FOR CAUSAL EFFECTS. Biometrika, 70(1), 41-55. doi:10.1093/biomet/70.1.41

Rosenberg, M. (1965). Society and the adolescent self-image. Princeton, NJ: Princeton University Press.

Rotter, J. B. (1966). Generalized expectancies for internal versus external control of reinforcement. Psychological monographs, 80(1), 1-28. doi:10.1037/h0092976

Sawyer, S. M., Azzopardi, P. S., Wickremarathne, D., \& Patton, G. C. (2018). The age of adolescence. Lancet Child \& Adolescent Health, 2(3), 223-228. doi:10.1016/s23524642(18)30022-1

Shenk, M. K., \& Scelza, B. A. (2012). PATERNAL INVESTMENT AND STATUS-RELATED CHILD OUTCOMES: TIMING OF FATHER'S DEATH AFFECTS OFFSPRING SUCCESS. Journal of Biosocial Science, 44(5), 549-569. doi:10.1017/s0021932012000053

Steinberg, L., \& Morris, A. S. (2001). Adolescent development. Annual Review of Psychology, 52, 83-110. doi:10.1146/annurev.psych.52.1.83

Słoczyński, T. (2015). New Evidence on Linear Regressionand Treatment Effect Heterogeneity. In (Vol. Discussion Paper No. 9491): The Institute for the Study of Labor (IZA).

UNICEF. (2016). The State of the World's Children 2016: A fair chance for every child. In: United Nations International Children's Emergency Fund.

Wooldridge, J. M. (2010). Econometric analysis of cross section and panel data. In: MIT press. 
Yeager, D. S., \& Dweck, C. S. (2012). Mindsets That Promote Resilience: When Students Believe That Personal Characteristics Can Be Developed. Educational Psychologist, 47(4), 302-314. doi:10.1080/00461520.2012.722805 


\section{Online Supplementary Material}

Table A1. Comparing characteristics at age 8 for non-attrited versus attrited index children in the older cohort

\begin{tabular}{lccr}
\hline & \multicolumn{3}{c}{ Ethiopia } \\
\cline { 2 - 4 } & Non-attrited & Attrited & Difference \\
\hline Proportion of males & 0.525 & 0.446 & 0.080 \\
Wealth Index & 0.221 & 0.273 & $-0.053^{* * *}$ \\
Observations & 813 & 184 & \\
Future Orphanhood & & & \\
Will lose father between 8-22 (but mother alive) & 0.124 & 0.038 & 0.086 \\
Will lose mother between 8-22 (but father alive) & 0.054 & 0.0384 & 0.016 \\
Will lose both parents between ages 8-22 & 0.023 & 0.906 & $-0.822 * * *$ \\
\hline
\end{tabular}


Table A2 Covariate balance summary (for treatment model that measures outcomes at age 15)

weighted

$\begin{array}{lll}\text { Treatment } & \text { Raw observations } & \text { observations }\end{array}$

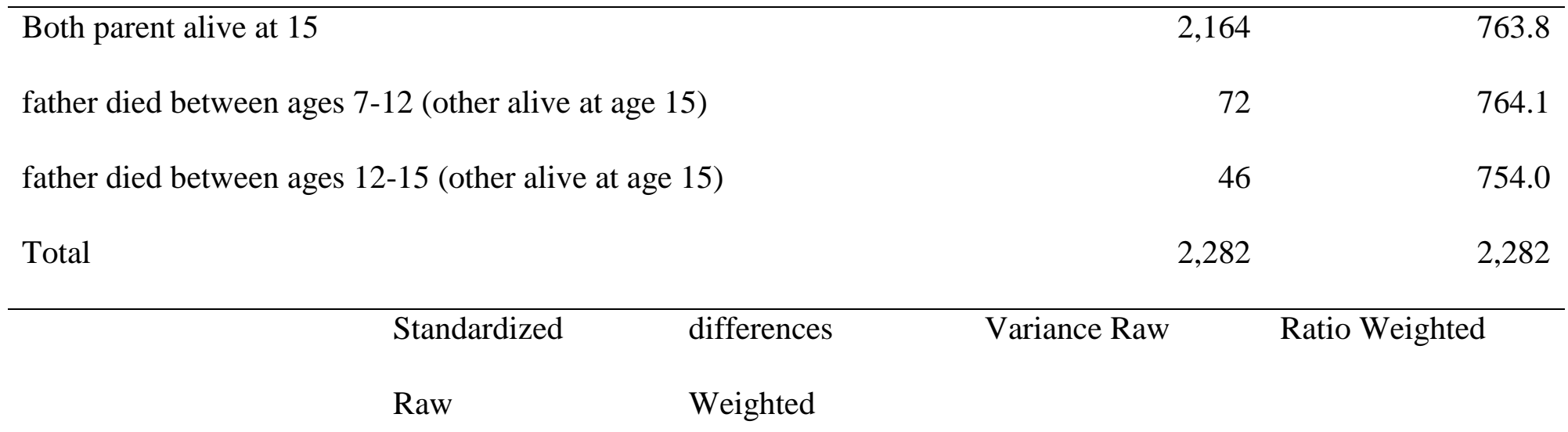

Father died between 7-12 (mother alive at age 15)

$\begin{array}{lllll}\text { Father's education } & -.0637791 & -.002976 & .8935337 & .9465988 \\ \text { Wealth index } & -.0588972 & -.0013521 & .9241059 & .909369 \\ \text { rural } & -.1238563 & -.0017101 & 1.107959 & 1.000993 \\ \text { Tigray } & -.2649285 & .002337 & .6088109 & 1.005818 \\ \text { Oromia } & .0743701 & .0044123 & 1.121045 & 1.005529 \\ \text { Addis Ababa } & -.0352146 & -.0000115 & .9315841 & .9999711\end{array}$


Father died between 12-15 (mother alive at age 15)

$\begin{array}{lllll}\text { Father's education } & -.1803964 & -.1265791 & .9451213 & .8721487 \\ \text { Wealth index } & .017164 & -.097052 & 1.120952 & .9574791 \\ \text { rural } & -.1411116 & .0088396 & 1.127872 & .9947974 \\ \text { Tigray } & -.1436813 & .0083586 & .80167 & 1.020854 \\ \text { Oromia } & -.1379957 & -.0364766 & .8083411 & .953443 \\ \text { Addis Ababa } & .2530756 & .0347505 & 1.617615 & 1.086659 \\ \text { Amhara } & -.1126978 & .0272904 & .8397412 & 1.030946\end{array}$


Table A3: Robustness check using OLS estimator: outcomes at 15 conditioned on characteristics at age 8 (both cohorts)

\begin{tabular}{|c|c|c|c|}
\hline & Agency & Self Esteem & Subjective wellbeing \\
\hline \multirow[t]{2}{*}{ father died 7-12 } & 0.05 & $-0.15^{* *}$ & $-0.89 * * *$ \\
\hline & $(0.073)$ & $(0.075)$ & $(0.194)$ \\
\hline \multirow[t]{2}{*}{ father died $12-22$} & -0.11 & -0.02 & $-0.34 *$ \\
\hline & $(0.071)$ & $(0.120)$ & $(0.183)$ \\
\hline \multirow[t]{2}{*}{ chsex } & 0.00 & 0.02 & 0.01 \\
\hline & $(0.028)$ & $(0.027)$ & $(0.084)$ \\
\hline \multirow[t]{2}{*}{ enrol } & 0.04 & -0.00 & 0.02 \\
\hline & $(0.026)$ & $(0.051)$ & $(0.086)$ \\
\hline \multirow[t]{2}{*}{ wi } & 0.19 & $0.58 * * *$ & $2.08 * * *$ \\
\hline & $(0.211)$ & $(0.168)$ & $(0.445)$ \\
\hline \multirow[t]{2}{*}{ lnhhsize } & -0.00 & -0.05 & $0.37 * * *$ \\
\hline & $(0.040)$ & $(0.047)$ & $(0.108)$ \\
\hline \multirow[t]{2}{*}{ rural } & -0.01 & 0.11 & $0.89 * * *$ \\
\hline & $(0.076)$ & $(0.070)$ & $(0.217)$ \\
\hline
\end{tabular}




\begin{tabular}{llll}
\hline Father's education & 0.00 & $0.01 * *$ & 0.01 \\
& $(0.004)$ & $(0.005)$ & $(0.013)$ \\
Mother's & $0.01^{* * *}$ & 0.01 & $0.05^{* * * *}$ \\
education & & & \\
& $(0.003)$ & $(0.005)$ & $(0.013)$ \\
Constant & -0.19 & 0.35 & -0.17 \\
& $(0.406)$ & $(0.550)$ & $(0.830)$ \\
Observations & 2,326 & 2,326 & 2,326 \\
R-squared & 0.035 & 0.058 & 0.099
\end{tabular}

Categorical dummies for region of residence included in estimation but results (mostly insignificant) not reported. Robust standard errors in parentheses $* * * \mathrm{p}<0.01, * * \mathrm{p}<0.05, * \mathrm{p}<0.1$ 
Table A4. Covariate balance summary (for treatment model that measures outcomes at age 22)

weighted

Treatment Raw observations observations

\begin{tabular}{|c|c|c|c|}
\hline \multicolumn{2}{|l|}{ Both parents alive at 22} & 588 & 217.2 \\
\hline \multicolumn{2}{|c|}{ Father died between ages 7-12 (mother alive at age 22 ) } & 30 & 2217.5 \\
\hline \multicolumn{2}{|c|}{ Father died between ages $12-22$ (mother alive at age 22 ) } & 54 & 237.3 \\
\hline \multicolumn{2}{|l|}{ Total } & 672 & 672.0 \\
\hline Standardized & differences & Variance Raw & Ratio Weighted \\
\hline Raw & Weighted & & \\
\hline
\end{tabular}

Father died between 7-12 (other alive at age 22)

$\begin{array}{llccc}\text { daded_est } & .1978655 & -.0016778 & 1.065141 & .9986177 \\ \text { wi } & .0763738 & -.0056427 & 1.100697 & 1.040191 \\ \text { rural } & .0719098 & .0136492 & .9629394 & .9858971 \\ \text { rtigray } & -.4406118 & -.001034 & .3773257 & .9964057 \\ \text { rorom } & .0238105 & -.003992 & 1.071602 & .9940366\end{array}$




$\begin{array}{lcccc}\text { ramhara } & .3328561 & -.0052085 & 1.416243 & .9971401 \\ \text { raddis } & -.1799715 & -.0030577 & .612712 & .9894412 \\ & & & & \\ \text { Father's educ*father's educ } & .1418282 & -.0016273 & 1.067229 & .9154865 \\ \text { Father's educ*wealth } & .0701166 & -.0036305 & 1.021989 & 1.050383\end{array}$

One parent died between 12-22 (mother alive at age 22)

$\begin{array}{lllll}\text { daded_est } & -.1163341 & .070046 & 1.105239 & .811646 \\ \text { wi } & .196525 & -.0338491 & 1.122386 & .9820198 \\ \text { rural } & -.3020624 & .1268876 & 1.19748 & .8594735 \\ \text { rtigray } & -.1797973 & .0322739 & .7537474 & 1.113725 \\ \text { rorom } & .0780873 & -.1828294 & 1.140122 & .718209 \\ \text { ramhara } & -.3454166 & -.0137292 & .5046697 & .9919785 \\ \text { raddis } & .230267 & -.0461136 & 1.573183 & .8445666\end{array}$

$\begin{array}{llll}\text { Father's educ*father's educ } & -.0397563 & -.00926 & 1.095087\end{array}$ 
A richer treatment model was specified by including an interaction terms to facilitate a better balance in the father's education variables for the group where the father died in early adolescence. 
Table A5a: Robustness Check: Outcomes at age 22 conditioned on pre-orphanhood characteristics

\begin{tabular}{|c|c|c|c|c|c|c|c|c|}
\hline \multirow{3}{*}{ VARIABLES } & \multirow{3}{*}{ Agency } & \multirow{3}{*}{$\begin{array}{l}\text { (7) } \\
\text { self_esteem }\end{array}$} & \multirow{3}{*}{$\begin{array}{l}\text { (8) } \\
\text { Subjective } \\
\text { wellbeing }\end{array}$} & \multirow{3}{*}{$\begin{array}{l}\text { (2) } \\
\text { peer_relat2 }\end{array}$} & \multirow{3}{*}{$\begin{array}{l}\text { (3) } \\
\text { leadteam }\end{array}$} & \multirow{3}{*}{$\begin{array}{l}(4) \\
\text { grit }\end{array}$} & \multirow{3}{*}{$\begin{array}{l}\text { (5) } \\
\text { con }\end{array}$} & \multirow{3}{*}{$\begin{array}{l}\text { (1) } \\
\text { self_efficacy2 }\end{array}$} \\
\hline & & & & & & & & \\
\hline & & & & & & & & \\
\hline \multirow[t]{2}{*}{ father died 7-12 } & 0.10 & 0.08 & 0.22 & -0.02 & -0.07 & -0.11 & -0.04 & -0.08 \\
\hline & $(0.008)$ & $(0.142)$ & $(0.212)$ & $(0.079)$ & $(0.116)$ & $(0.084)$ & $(0.097)$ & $(0.088)$ \\
\hline \multirow{3}{*}{$\begin{array}{l}\text { father died 12- } \\
22\end{array}$} & $0.11 *$ & 0.20 & -0.21 & $0.21 * *$ & -0.00 & 0.01 & 0.09 & $0.13^{*}$ \\
\hline & & & & & & & & \\
\hline & $(0.069)$ & $(0.127)$ & $(0.244)$ & $(0.084)$ & $(0.088)$ & $(0.097)$ & $(0.088)$ & $(0.064)$ \\
\hline \multirow[t]{2}{*}{ chsex } & $0.14 * *$ & 0.04 & -0.10 & $0.18^{* * *}$ & $0.16^{* *}$ & $0.12 * *$ & $0.07 *$ & $0.14 * * *$ \\
\hline & $(0.057)$ & $(0.057)$ & $(0.142)$ & $(0.047)$ & $(0.062)$ & $(0.053)$ & $(0.039)$ & $(0.043)$ \\
\hline \multirow[t]{2}{*}{ wi } & 0.13 & $0.71 * *$ & $1.79 * * *$ & -0.16 & -0.09 & $-0.38^{*}$ & -0.23 & 0.15 \\
\hline & $(0.227)$ & $(0.263)$ & $(0.584)$ & $(0.215)$ & $(0.232)$ & $(0.205)$ & $(0.169)$ & $(0.144)$ \\
\hline Father's & 0.01 & 0.02 & 0.00 & 0.00 & 0.01 & $0.02 * * *$ & 0.01 & $0.02 * *$ \\
\hline education & & & & & & & & \\
\hline
\end{tabular}




\begin{tabular}{lllllllll}
\hline & $(0.006)$ & $(0.011)$ & $(0.022)$ & $(0.006)$ & $(0.008)$ & $(0.006)$ & $(0.007)$ & $(0.007)$ \\
Mother's & $0.01^{*}$ & 0.01 & 0.00 & 0.01 & 0.01 & $-0.01^{*}$ & 0.00 & -0.00 \\
education & & & & & & & \\
& & & & & & & & \\
& $(0.007)$ & $(0.011)$ & $(0.023)$ & $(0.009)$ & $(0.008)$ & $(0.006)$ & $(0.009)$ & $(0.009)$ \\
School & $0.10^{*}$ & 0.09 & -0.06 & 0.01 & 0.10 & $0.07 *$ & $0.08^{* *}$ & 0.03 \\
Enrolment & & & & & & & $(0.039)$ & $(0.058)$ \\
& $(0.052)$ & $(0.067)$ & $(0.132)$ & $(0.059)$ & $(0.068)$ & $(0.039)$ & 673 & 673
\end{tabular}

Ordinary least squares (OLS) estimates. Dependent variable respective non-cognitive outcome at age 22. Other control variables included in the estimation but unreported are age in months, school enrolment status, region of residence, , rural residence, log of household size. Robust standard errors in parentheses $* * * \mathrm{p}<0.01, * * \mathrm{p}<0.05, * \mathrm{p}<0.1$

Table A5b: Robustness Check: Outcomes at age 22 conditioned on pre-orphanhood characteristics 


\begin{tabular}{|c|c|c|c|c|c|c|c|c|}
\hline & agency & self_esteem & cladder & peer_relat & leadteam & grit & consc. & self_efficacy \\
\hline \multirow[t]{3}{*}{ father died 7- } & 0.10 & 0.08 & 0.22 & -0.02 & -0.07 & -0.11 & -0.04 & -0.08 \\
\hline & & & & & & & & \\
\hline & $(0.086)$ & $(0.142)$ & $(0.212)$ & $(0.079)$ & $(0.116)$ & $(0.084)$ & $(0.097)$ & $(0.088)$ \\
\hline \multirow{3}{*}{$\begin{array}{l}\text { father died } \\
12-15\end{array}$} & 0.08 & 0.04 & -0.58 & 0.15 & -0.04 & -0.02 & 0.07 & 0.08 \\
\hline & & & & & & & & \\
\hline & $(0.116)$ & $(0.166)$ & $(0.535)$ & $(0.122)$ & $(0.152)$ & $(0.139)$ & $(0.155)$ & $(0.146)$ \\
\hline \multirow{3}{*}{$\begin{array}{l}\text { father died } \\
15-22\end{array}$} & 0.13 & $0.28 * *$ & -0.05 & $0.23 * *$ & 0.02 & 0.02 & 0.10 & $0.15^{*}$ \\
\hline & & & & & & & & \\
\hline & $(0.077)$ & $(0.129)$ & $(0.213)$ & $(0.085)$ & $(0.090)$ & $(0.107)$ & $(0.098)$ & $(0.079)$ \\
\hline Observations & 673 & 673 & 673 & 673 & 673 & 673 & 673 & 673 \\
\hline R-squared & 0.091 & 0.087 & 0.044 & 0.114 & 0.081 & 0.068 & 0.079 & 0.11 \\
\hline
\end{tabular}

Robust standard errors in parentheses

$* * * \mathrm{p}<0.01, * * \mathrm{p}<0.05, * \mathrm{p}<0.1$ 
